\title{
Phospholipid signaling in innate immune cells
}

\author{
Valerie B. O'Donnell, ' Jamie Rossjohn, ${ }^{1,2,3}$ and Michael J.0. Wakelam ${ }^{4}$ \\ 'Systems Immunity Research Institute and Division of Infection and Immunity, School of Medicine, Cardiff University, Cardiff, United Kingdom. Infection and Immunity Program and Department of \\ Biochemistry and Molecular Biology, Biomedicine Discovery Institute, Monash University, and ${ }^{3}$ ARC Centre of Excellence in Advanced Molecular Imaging, Monash University, Clayton, Victoria, Australia. \\ ${ }^{4}$ Babraham Institute, Babraham Research Campus, Cambridge, United Kingdom.
}

\begin{abstract}
Phospholipids comprise a large body of lipids that define cells and organelles by forming membrane structures. Importantly, their complex metabolism represents a highly controlled cellular signaling network that is essential for mounting an effective innate immune response. Phospholipids in innate cells are subject to dynamic regulation by enzymes, whose activities are highly responsive to activation status. Along with their metabolic products, they regulate multiple aspects of innate immune cell biology, including shape change, aggregation, blood clotting, and degranulation. Phospholipid hydrolysis provides substrates for cell-cell communication, enables regulation of hemostasis, immunity, thrombosis, and vascular inflammation, and is centrally important in cardiovascular disease and associated comorbidities. Phospholipids themselves are also recognized by innate-like T cells, which are considered essential for recognition of infection or cancer, as well as self-antigens. This Review describes the major phospholipid metabolic pathways present in innate immune cells and summarizes the formation and metabolism of phospholipids as well as their emerging roles in cell biology and disease.
\end{abstract}

Circulating innate immune cells, including neutrophils, platelets, monocytes, eosinophils, and mast cells, are considered resting basally. However, they rapidly activate during injury, such as bleeding or trauma, to trigger hemostasis and prevent bacterial invasion. Major metabolic changes to the lipid pool that accompany innate immune activation are essential in orchestrating an effective innate immune response and then initiating the process of wound healing and repair. This cellular activation is exemplified by multifaceted alterations to the phospholipid (PL) pool and includes (a) membrane remodeling and generation of potent bioactive signaling mediators from PL-derived substrates (lysophospholipids [lysoPLs], oxylipins, platelet-activating factor [PAF], etc.); (b) aminophospholipid (aPL) externalization, providing a negatively charged membrane that supports clotting factor activities on the cell surface; (c) generation of large numbers of enzymatically oxidized PLs (eoxPLs), which are required for hemostasis, and (d) PL headgroup phosphorylation that occurs within seconds, leading to formation of transient membrane anchors for kinases that regulate GPCR signaling, endocytosis, apoptosis, and cytokinesis.

Separate from changes to the PL pool, lipid-reactive T cells restricted to the CD1 family of antigen-presenting molecules can sense the presence of bacterially derived lipids, self-lipids during thymic selection, and self-lipids that may be perturbed during cellular stress (1, 2). Many lipid-reactive T cells appear nonreactive to common PLs normally found within the cell membrane. However, T cells reactive to bacterially derived PLs $(3,4)$, rare PLs (5), and lysoPLs expressed on certain tumors $(6,7)$ have been described. These processes will be described in detail below.

Conflict of interest: The authors have declared that no conflict of interest exists. Reference information: J Clin Invest. 2018;128(7):2670-2679.

https://doi.org/10.1172/JCI97944.
PLs represent a diverse group of lipids also known as glycerophospholipids, described using LIPID MAPS (http://www.lipidmaps.org/) nomenclature. The five classes are subdivided based on polar headgroup and include phosphatidylcholine (PC), phosphatidylethanolamine (PE), phosphatidylglycerol (PG), phosphatidylinositol (PI), and phosphatidylserine (PS). Within each class, molecular species are differentiated by fatty acid (FA) substitution at the $s n 1$ and $s n 2$ positions of the glycerol backbone (Figure 1A). Generally, sn1 FAs are saturated or monounsaturated, whereas $s n 2$ are polyunsaturated (PUFA) with longer acyl chains. While the $s n 2$ FA is always an acyl substituent, the $s n 1$ for PE or PC can be either alkyl-linked (ether-linked) or 1Z-alkenyl-linked (plasmalogen), with the latter particularly abundant in circulating immune cells (Figure 1B). Thus, blood cells contain literally hundreds of unique PL species, although the most quantitatively abundant contain a relatively restricted set of FAs: palmitic acid (16:0), stearic acid (18:0), or oleic acid (18:1) at sn1; and linoleic acid (LA; 18:2), arachidonic acid (AA;20:4), eicosapentaenoic acid (EPA; 20:5), or docosahexaenoic acid (DHA; 22:6) at sn2 (Figure 1, C and D). Overall, AA is present in PLs at least at 10 -fold higher concentrations than other PUFAs at sn 2 in immune cells. Dietary intake of FAs, through ingestion of high doses of fish oils, can influence relative levels of omega-3 (DHA, EPA) versus omega-6 (AA, LA) fatty acids in blood cell PLs $(8,9)$. Whether this leads to changes in PL-mediated signaling in the innate immune system is unknown. However, it directly influences levels of oxylipins generated in serum, with higher levels of some omega-3-derived species observed (10-15).

PLs are synthesized and remodeled through several interconnected enzyme pathways, including the Kennedy pathway (PC, PE synthesis), the cytidine diphosphate diacylglycerol (CDP-DAG) pathway (synthesis of PS and PI from PA), and the Lands cycle (FA removal and reattachment to PLs) (refs. 16-18 and Supplemental Figure 1, A and B; supplemental material available online 
A
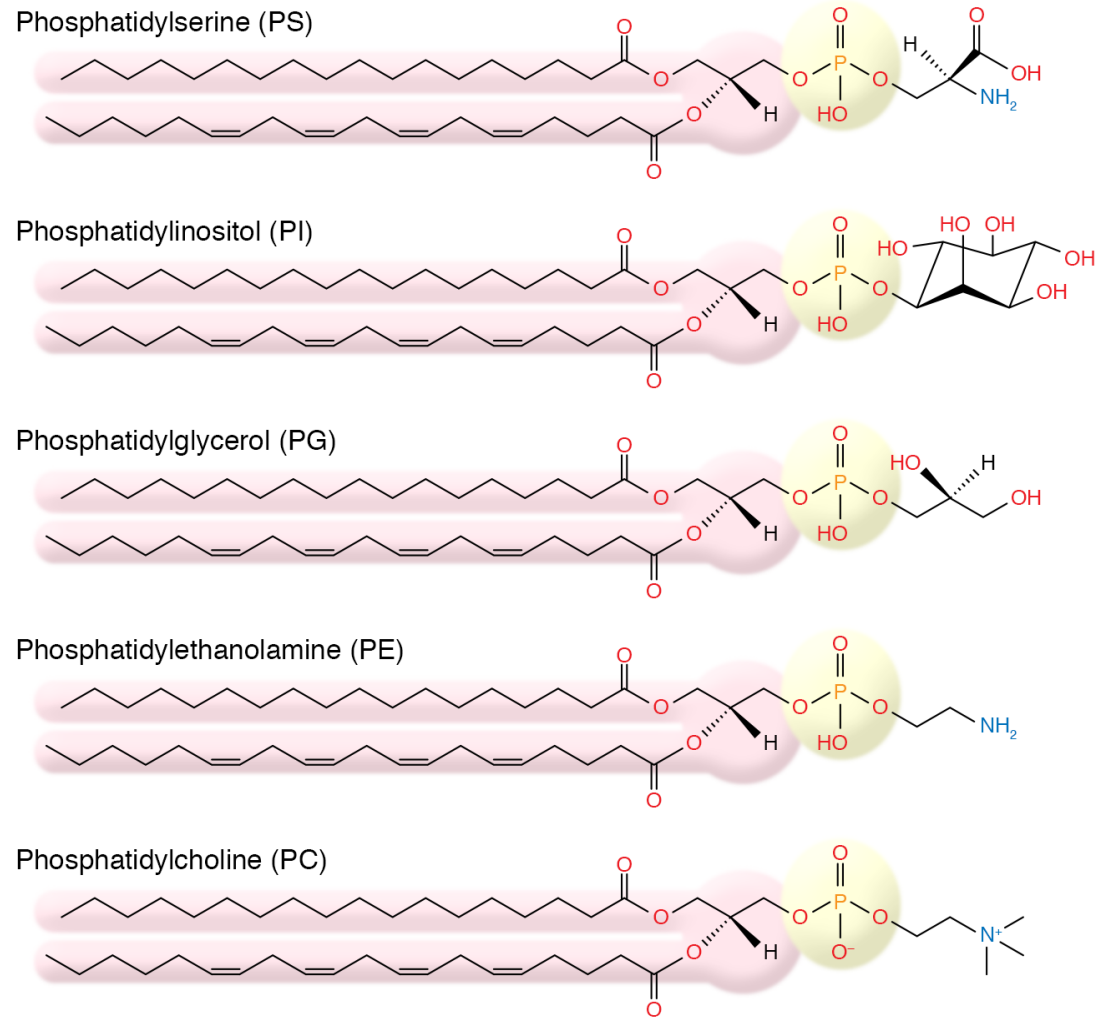

B
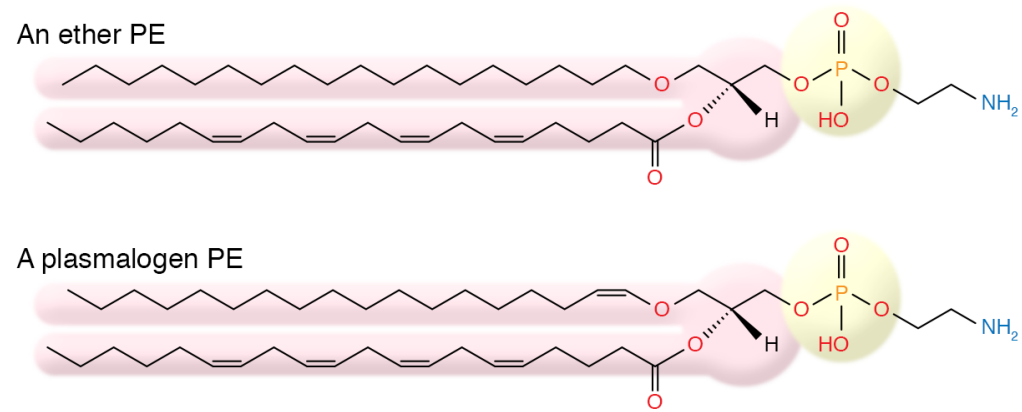

C

Palmitic acid

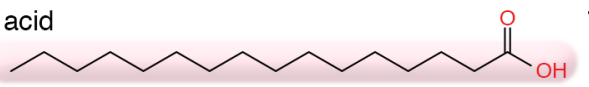

Stearic acid

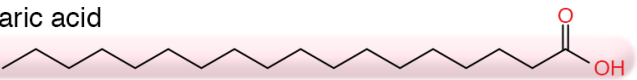

Common sn1 fatty acids

Oleic acid

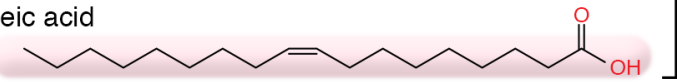

D

Linoleic acid

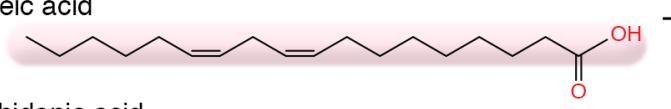

Arachidonic acid

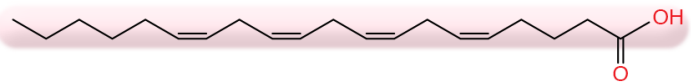

Eicosapentaenoic acid

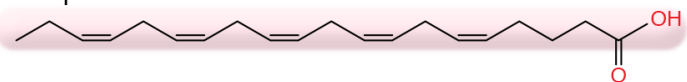

Docosahexaenoic acid

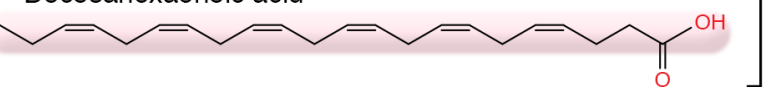

Figure 1. Structures of the major PL classes. (A)

The five PL classes: phosphatidylserine (PS), phosphatidylinositol (PI), phosphatidylglycerol (PC), phosphatidylethanolamine (PE), and phosphatidylcholine (PC). (B) Ether and plasmalogen PLs. (C) Structures of common sn1 fatty acids in PLs. (D) Structures of common sn2 fatty acids in PLs.

with this article; https://doi.org/10.1172/ JCI97944DS1). These are common to all cell types, including circulating blood cells, and are subject to dynamic regulation depending on metabolic state. The Lands cycle controls substrate supply for bioactive lipid signaling and is described in more detail below.

Following an acute injury, circulating cells become trapped at the wound site. The resulting clot composition is highly dependent on vessel type and coexisting inflammation (19-21). Concurrently, trapped cells are exposed to soluble protein and nonprotein mediators that activate receptor-dependent processes, including tissue factor, collagen, thrombin, ADP, damage-associated molecular patterns, and pathogen-associated molecular patterns (PAMPs). PAMPs include bacterial products such as lipopolysaccharide (LPS) and f-met-leu-phe (fMLP), both of which stimulate cells in the nanogram range. LPS acts via TLR complexes, while fMLP mediates signaling via a GPCR called FPR1. At the same time, a cascade of cell activation processes characterized by extracellular calcium influx and release from intracellular stores are associated with PL hydrolysis. This is mediated by several types of phospholipases, broadly categorized as PLA, PLA, PLC, and PLD and named by site of PL hydrolysis. Each comprises families of multiple isoforms (Figure 2A). Many different phospholipases are acutely switched on in activated blood cells, and their coordinated activities are responsible for initiating cell activation during the injury response. This controls much of the signaling that leads to lipid membrane remodeling and a plethora of lipid-dependent bioactivities, both intracellular and extracellular. Lipids generated during initial phospholipase activity are either released as secondary paracrine mediators (e.g., oxylipins), or retained in the cells to act locally, either physically changing membrane structure (e.g., eoxPL) or signaling at intracellular nuclear receptors (e.g., FA activation of PPARs). The following sections describe PL metabolism in innate immune cells in more detail. 
A

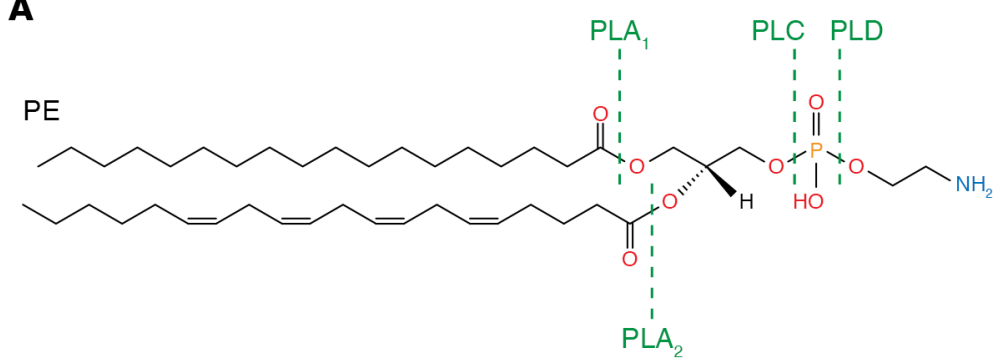

B

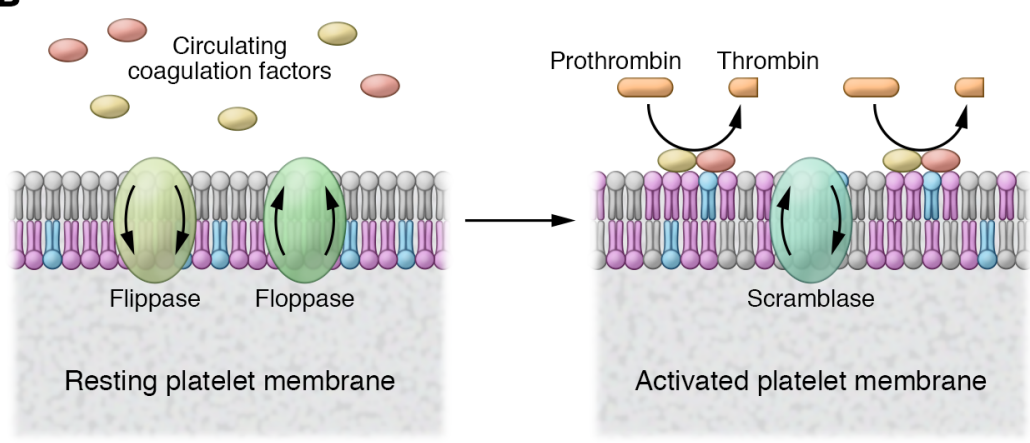

Figure 2. PL cleavage and PL asymmetry in innate immune cells. (A) Phospholipases PLA, $\mathrm{PLA}_{2}, \mathrm{PLC}$, and PLD hydrolyze PLs and are named by the site of hydrolysis, as shown. (B) Flippase and floppase enzymes maintain membrane symmetry on resting platelet membranes. Upon activation, calcium-dependent externalization of $\mathrm{PE}$ and $\mathrm{PS}$ provides a negatively charged surface that supports coagulation factor binding and facilitates prothrombin's conversion to active thrombin. $X$ and $V$, zymogen coagulation factors $\mathrm{X}$ and $\mathrm{V} ; \mathrm{Xa} / \mathrm{Va}$, a complex of activated factor $\mathrm{X}$ and factor $V$ (prothrombinase complex).

$\simeq \mathrm{PC} \leftrightharpoons \mathrm{PE} \leftrightharpoons \mathrm{PS}$

$\bigcirc x \bigcirc \mathrm{V} \bigcirc \mathrm{xa} / \mathrm{Na}$

\section{PLA ${ }_{2}$-mediated PL hydrolysis forms lysoPLs and FAs}

Pathophysiological activation of innate cells triggers immediate cell membrane hydrolysis by phospholipases. The best-studied are PLA $_{2}$ isoforms, which comprise approximately 16 groups and several subgroups, with six main PLA $_{2}$ subtypes (22). PLA removes fatty acyl groups from the $s n 2$ position of PLs, leading to lysoPL and FA generation and thereby supporting the first step in bioactive oxylipin formation (Figure 2A). Several lysoPLs are generated during platelet activation, including lysoPE, lysoPC, lysoPI, and lysoPS (23). Leukocytes and platelets express at least three classes of PLA : secretory (sPLA ${ }_{2}$; groups II and X), calcium-dependent ( $\mathrm{CPLA}_{2}$; group IV), and calcium-independent (iPLA ${ }_{2}$; group VI), while several others are known to exist in other cells. Another PLA $\mathrm{A}_{2}$ isoform, termed PAF-acetyl hydrolase (PAF$\mathrm{AH}$ ), is found in the circulation (24).

Regulation of innate immune cell PLA $_{2}$ is multifaceted and complex. For example, in monocytes, both MAPK-catalyzed phosphorylation and PKC activate $\mathrm{CPLA}_{2} \alpha$ (25). For many years, $\mathrm{CPLA}_{2} \alpha$ was considered the primary source of AA for eicosanoid generation, but recent studies show a major role for PLAA $_{2}$ in several circulating cell types. In this regard, platelet $\mathrm{CPLA}_{2} \alpha$ can catalyze AA release from innate immune PL pools in response to collagen, enabling generation of thromboxane $\mathrm{A}_{2}$ and 12-HETE (26). However, $\mathrm{iPLA}_{2} \gamma$ is required to mobilize AA from plasmalogen PEs and PGs for ADP-induced thromboxane $\mathrm{B}_{2}$ generation (27). Thus, different PLA ${ }_{2}$ isoforms couple to distinct receptor pathways, though both can facilitate platelet eicosanoid generation. Similarly, in leukocytes, $\mathrm{CPLA}_{2} \alpha$ and iPLA $\beta$ act together to provide different signaling lipids at separate intracellular sites, with both required for migration in response to MCP-1 (also known as CCL2) (28).
Importantly, PLA ${ }_{2}$ provides the essential link between PL metabolism and cyclooxygenase-mediated (COX-mediated) pathways in immune cells, e.g., generation of thromboxane in platelets, and prostaglandin $\mathrm{E}_{2}\left(\mathrm{PGE}_{2}\right)$ in inflammation, both of which require AA. COX-1 and COX-2 are the well-known targets of aspirin, NSAIDs, and more recently developed COX-2-selective NSAIDs, underscoring their clinical importance in vascular and chronic inflammatory disease.

Circulating blood cells express several sPLA ${ }_{2}$ isoforms, including group IIA (platelets, leukocytes), group X (neutrophils), and group III (mast cells). Group IIA sPLA ${ }_{2}$ attacks bacterial membranes during host defense in innate immunity, while group III targets stromal fibroblasts. PG and PE are the primary targets of group IIA, with host cells being relatively protected because PC comprises most of the external membrane leaflet of healthy cells. In contrast, in mast cells, group III sPLA ${ }_{2}$ attacks stromal cells via AA release and its metabolism to prostaglandin $\mathrm{D}_{2}$, promoting mast cell maturation and ultimately anaphylaxis (29).

Hydrolysis of the $s n 1$ fatty acyl group can also result in lysoPL and FA release, in this case due to PLA 1 (Figure 2A). Little is known about PLA in immune cells, although a fast release of saturated FAs occurs upon platelet activation (30). A platelet PLA isoform was purified in 2011 and proposed as a source of circulating lysoPA generated during clotting, acting in concert with autotaxin to mediate sequential hydrolysis of cellular PC (31).

Regulation of $\mathrm{PLA}_{2}$ isoforms in innate immune cells is complex, given the large number of gene products, varied cell expression, intracellular localization, activation, control, etc. For further information on this topic, the reader is directed toward several recent reviews $(25,29,32)$.

Phospholipases and their products play multiple and complex roles in disease, with symptoms noted well beyond the innate immune system. Deficiency of $\mathrm{CPLA}_{2} \alpha$ in humans leads to major 
A

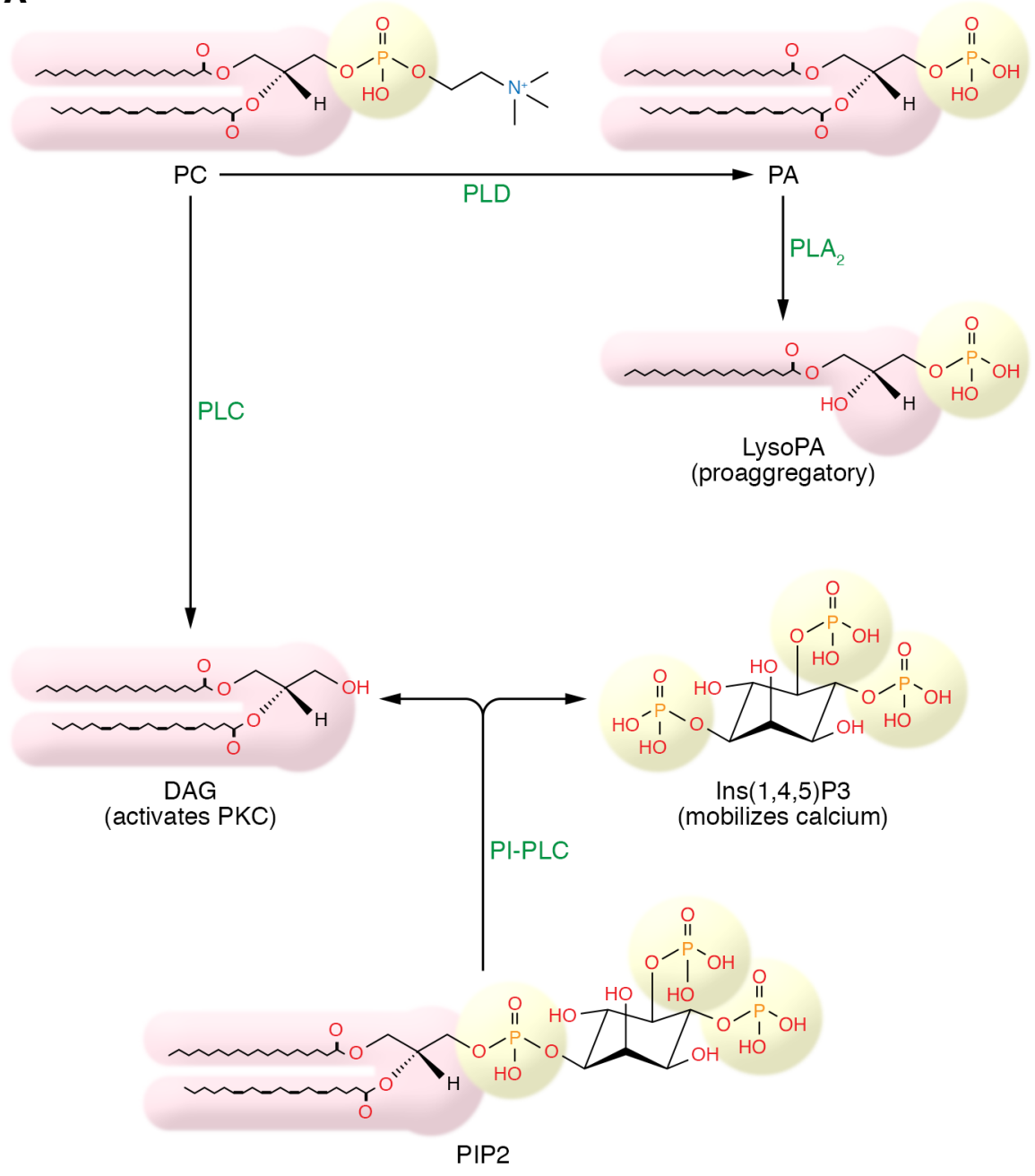

B

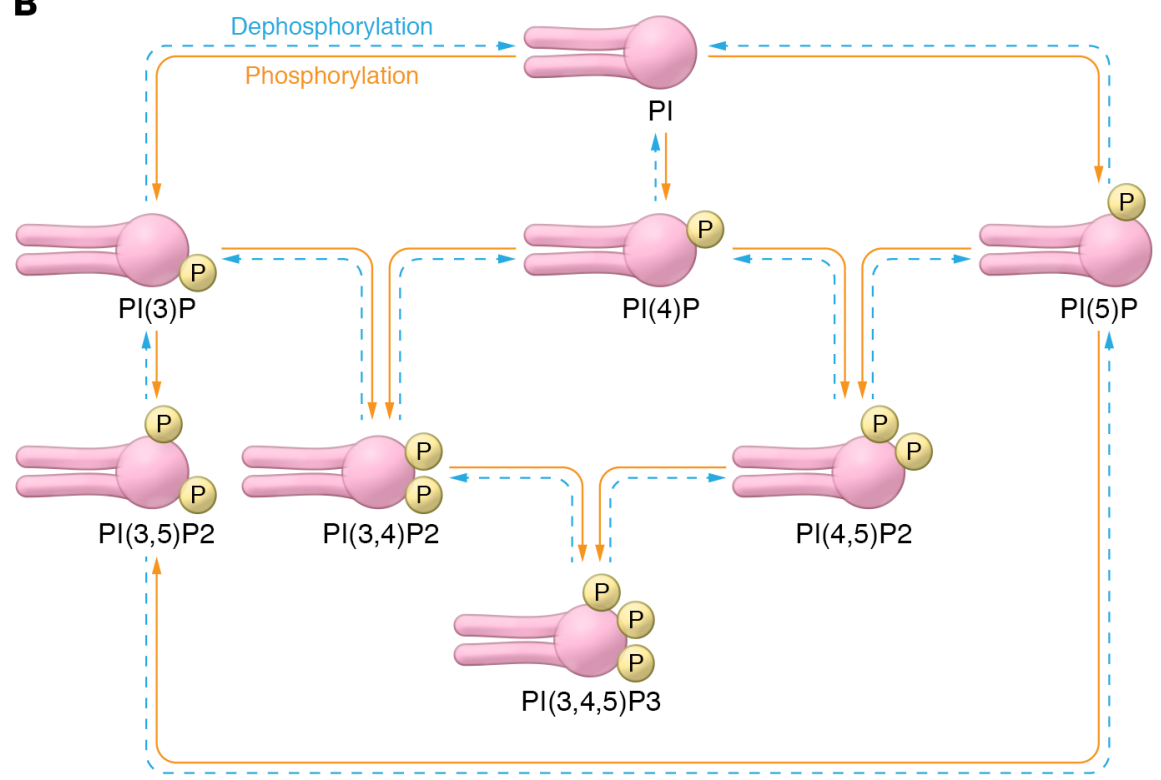

Figure 3. PLC, PLD, and phosphoinositide pathways. (A) PLC and PLD generate lipid intermediates that promote innate immunity. (B) PI is phosphorylated/dephosphorylated by a series of known enzymes, generating a complex array of transient lipid molecular species, which display potent bioactivity. gastrointestinal complications including bleeding, as well as increased susceptibility to infection, and acute respiratory distress syndrome. A lack of platelet thromboxane $\mathrm{B}_{2}$ is associated with platelet defects (25). On the other hand, mice lacking $\mathrm{CPLA}_{2} \alpha$ are protected from hepatic liver deposition and fibrosis (25). Deficiency of iPLA $\beta$ is linked with several diseases, including neurological, cancer, vascular, and immune (32). In terms of inflammation, $\mathrm{iPLA}_{2} \beta$ is required for macrophage spreading and adhesion (32). Inhibitor studies have shown that CPLA 2 and iPLA $_{2}$ isoforms are critical for development of autoimmune disease, such as experimental autoimmune encephalomyelitis (32).

\section{Scramblase activities leading to aPL externalization}

Normally, circulating blood cells maintain an asymmetric plasma membrane, with PC the most abundant externally facing phospholipid and PE/PS primarily located on the cytosolic surface. PE and PC each make up about $40 \%$ of total PL in blood cells, with PS being only a few mole percent $(33,34)$. Maintaining asymmetry is an energy-requiring process using flippase and floppase enzymes to prevent exposure of the negatively charged aminophospholipids (aPLs) PS and PE on the outside of the cells. Upon activation and calcium mobilization, platelets rapidly activate scramblase, leading to externalization of aPLs (Figure 2B) $(35,36)$. This changes the biophysical nature of the membrane to allow coagulation factors to bind and work effectively to generate fibrin. Scott syndrome has been identified as a genetic defect in aPL externalization, that manifests as a relatively mild bleeding phenotype (37). This has been localized to mutations in TMEM16F, a protein proposed to play dual roles as both a channel and a scramblase (38).

Coagulation factors comprise a series of serine proteases and associated cofactors that are largely inactive in the fluid phase of blood. In order to facilitate clot formation, they must self-associate on a negatively charged surface, where they reach a high local concentration. This is classically achieved by platelets externalizing PE/PS following agonist activation $(35,36)$. The headgroup of PS facilitates calcium binding to the surface, which ultimately allows binding of negatively charged $\gamma$-carboxyglutamic (Gla) domains of factors at the cell membrane (Figure 2B). PE and eoxPL enhance 
the ability of PS to support Gla domain binding $(39,40)$, a recent discovery that is described in more detail below. Platelets contain several molecular species of PE and PS. The optimum FA composition to support coagulation is around 18-20 carbons, with typical unsaturation seen in platelet PLs, though plasmalogen and acyl forms of PE are equally effective in this context (41). Recent studies show that PE and PS associate on the surface of platelets in defined microdomains, forming "cap" structures (42). This may further enhance hemostasis by reducing the surface area available, leading to higher local concentrations of coagulation factors on the cells.

$\mathrm{PE} / \mathrm{PS}$ externalization is often measured using annexin V, which binds to negatively charged membranes via electrostatic interactions, similarly to coagulation factors (43-45). Often, annexin $\mathrm{V}$ positivity is described as PS externalization, but it can also bind PE. Another protein, lactadherin, is reportedly PSspecific $(46,47)$. During inflammation, apoptotic innate immune cells can lose membrane asymmetry, also leading to PE/PS externalization (34). This is particularly relevant in the case of neutrophils, which undergo apoptosis following infection. Neutrophil apoptosis occurs alongside elevated coagulation during systemic infection and sepsis, suggesting a mechanistic link between neutrophil aPL exposure and associated coagulation (48).

\section{Generation and action of eoxPL in innate immunity}

Oxidized PCs with truncated FAs containing reactive aldehydes at the sn2 position have long been known to be generated nonenzymatically (49-52). They are detected in atheroma lesions and in the circulation during a myocardial infarction caused by plaque rupture (53). In contrast, several families of enzymatically oxidized PL (eoxPL), comprising eicosanoids/prostaglandins attached to PLs, were recently discovered. Circulating blood cells (neutrophils, platelets, eosinophils) and resident murine peritoneal macrophages generate eoxPL in a controlled manner as part of the innate immune response (40,54-59). They form via the catalytic activities of lipoxygenases (LOXs) as well as COX-1 (Supplemental Figure 2A). The most abundant eoxPLs are PEs, but PC forms are also found, and low levels of PI analogs were recently detected in platelets (60). PC and PE eoxPLs form as both plasmalogen and acyl species.

For many years, LOX isoforms were best known to generate monohydroperoxide derivatives of free-acid PUFAs, primarily AA (HpETEs), but also DHA (HpDOHEs) and LA (HpODEs). Cellular glutathione peroxidases (GPx) rapidly reduce lipid hydroperoxides to form hydroxyeicosatetraenoic acids (HETEs), hydroxydocosahexaenoic acids (HDOHEs), and hydroxyoctadecadienoic acids (HODEs), respectively. Positional isomers of these are generated in a cell-specific manner due to LOX expression patterns, e.g., by 5-LOX (5-HETE in neutrophils, monocytes), 15-LOX (15-HETE, 17-HDOHE in human eosinophils), and 12-LOX (12HETE, 14-HDOHE in platelets). In mice, 15-LOX is represented by a $12 / 15$-LOX gene product, with an expression pattern similar to that in human cells, that generates primarily 12-HETE and 14-HDOHE. This isoform is also highly expressed in murine peritoneal macrophages and is inducible by Th2 cytokines. Since AA is present in PL in at least 10-fold higher concentrations in immune cells than other PUFAs, its monohydroxylated products are the most abundant; for example, 12-HETE is the predominant eicosanoid generated by human platelets.
Most LOXs will only utilize free-acid PUFAs due to steric hindrance at the active site; however, 15-LOX (12/15-LOX in mice) can uniquely oxidize PLs (61). Thus, eoxPLs generated via 5- or 12-LOXs require a cycle of hydrolysis and re-esterification, involving $\mathrm{PLA}_{2}$ and membrane-bound $O$-acyltransferase/lysophosphatidate acyltransferase (MBOAT/LPAT) activities, while those from 15- or 12/15-LOX do not (Supplemental Figure 2B and refs. 40, $56,58)$. This is consistent with observations that neutrophil or platelet HETE-PLs are generated following agonist activation of cells to trigger $\mathrm{PLA}_{2}$, while eosinophil/macrophage HETE-PLs are detected under basal conditions $(40,56,58,59)$. Similarly, eoxPLs containing COX-1 products, such as $\mathrm{PGE}_{2}-\mathrm{PEs}$, require a cycle of hydrolysis and re-esterification (54).

Circulating innate immune cells and platelets generate eoxPLs via coordinated signaling pathways mediated by receptor-dependent calcium mobilization within 2-5 minutes of activation $(40,54,56)$. Unlike free-acid oxylipins, the cells retain eoxPLs within the membrane compartment and do not secrete them, suggesting a different biological role to their free analogs. Up to 2016, only small numbers of eoxPLs were known, typically 4 to 6 per cell type. However, studies using high-resolution lipidomics recently showed that human platelets generate over 100 unique molecular forms (30). The most abundant are 12-HETEPLs, in line with the relative abundance of platelet 12-HETE. However, multiple oxidized forms of AA are detected in platelet eoxPLs, along with monohydroxylated forms of rarer FAs (DHA, EPA, and others) (30). EoxPLs that contain thromboxane $B_{2}$ have never been detected, despite the abundance of this platelet lipid, suggesting that not all oxylipins are substrates for re-esterification. A recent study demonstrated that specific oxylipins serve as substrates for acyl-CoA synthetases, which activate these to produce an oxylipin-CoA species. This species then can be utilized by an acyltransferase (like MBOATs) to esterify the oxylipin into $\mathrm{PL}$, indicating that cellular control of eoxPL formation may occur at this level (62). Furthermore, correlation analysis of eoxPLs from platelets shows clustering into structurally related groups, further supporting the idea that their formation is dictated at least in part by the oxidized FA structure and resulting specificity of esterification pathways (39).

EoxPLs display multiple biological activities relevant to innate immunity and inflammation regulation. In neutrophils, HETE-PEs promote antibacterial activities, including enhancement of IL-8 release and neutrophil extracellular traps formation, while macrophage KETE-PEs are low-affinity agonists for PPAR $\gamma(56,57)$. Recently, HETE-PEs and -PCs were shown to be potently procoagulant as a result of their enhancement of PS binding to coagulation factors (Supplemental Figure 3A and ref. 39). In this, the lipids' oxidation epitope enhances the overall electronegative character of the plasma membrane, facilitating calcium interactions with PS that are required for blood clotting. Related to this, eoxPLs are significantly elevated in circulating cells in patients with the thrombotic disorder antiphospholipid syndrome, and mice lacking either platelet or eosinophil LOX isoforms display a venous bleeding defect that can be corrected by eoxPL administration $(39,63)$. EoxPLs also are immunogenic in vivo, with elevated eoxPL-specific IgG detected in antiphospholipid syndrome patients (39). 


\section{PAF, a plasmenylcholine with potent signaling activities}

PAF is a structurally unique plasmenylcholine (alkyl bond at $s n 1$ ) with an acetyl group at the $\operatorname{sn} 2$ position that signals at extremely low concentrations (around $10^{-14} \mathrm{M}$ ) via the PAF receptor, a GPCR, stimulating multiple signaling cascades (Supplemental Figure 3B). The PAF receptor is expressed by numerous blood cells, including neutrophils, monocytes, eosinophils, and platelets (64). It triggers multiple biological actions, including aggregation, calcium mobilization, superoxide release, eicosanoid generation, chemotaxis, adhesion, and cytokine generation in multiple circulating cell types, including platelets, neutrophils, and eosinophils (65).

PAF is generated via both remodeling and de novo pathways $(66,67)$ (Supplemental Figure 3B). Remodeling is the prominent biological mechanism and involves replacing an acyl with an acetyl moiety at the $s n 2$ position. De novo generation involves acetylation, dephosphorylation, and PC addition to a lysoPA; this last step is thought to be the source of endogenous PAF for homeostatic functions (67).

Two enzymes are involved in dynamically modulating PAF levels in the circulation. An acetyltransferase generated by circulating neutrophils and monocytes metabolizes lysoPAF to PAF through addition of an acetyl group at the $s n 2$ position. This is the prominent source of PAF during inflammation and allergies (68). On the other hand, PAF is removed by the action of PAF-acetyl hydrolase (PAF-AH), a circulating enzyme generated by multiple cell types, including innate immune blood cells. Platelets are also a source of PAF that is generated during aggregation.

Several studies have evaluated the potential for circulating PAF to act as a biomarker/predictor of cardiovascular disease or events. Despite its association with higher disease burden, PAFAH itself may represent a target for cardiovascular prevention, since PAF metabolism can lead to generation of proinflammatory lipids, such as lysoPC and lysoPAF. This concept led to extensive evaluation of reversible PAF-AH inhibitors, such as darapladib, in trials; however, these yielded mixed results, lacking sufficient effect on primary endpoints (24).

\section{PLC in innate immune signaling}

PLCs are a class of enzymes that cleave PLs on the glyceride side of the phosphodiester bond, leading to diacylglycerol (DAG) formation and release of the phosphorylated PL headgroup (Figure 3A). PI-specific PLCs are the most important PLCs in immune cells, comprising approximately 13 enzymes represented by six isotypes that play key roles in signal transduction (69). PI-PLC hydrolyzes PI-4,5-bisphosphate (PIP2) to form DAG and the inositol-trisphosphate Ins $(1,4,5) \mathrm{P} 3$, which in turn can activate PKC and mobilize intracellular calcium, respectively, to regulate both acute and chronic responses in immune cells. PLCs are activated by GPCRs and tyrosine kinase-linked receptors (RTKs) in platelets and leukocytes. RTK-activated PLC $\gamma$ subtypes are the most important in these cells, playing key roles in supporting neutrophil respiratory burst, phagocytosis, adhesion, and cell migration. PLC $\gamma 2$ is important for hemostasis: mice lacking this isoform exhibit a bleeding defect, with glycoprotein VI- and CLEC-2-dependent platelet responses abolished (70-74). This isoform also plays a role in platelet-dependent clot retraction
(75). Mast cells, NK cells, and murine neutrophils express both PLC $\gamma 1$ and PLC $\gamma 2$ isoforms (76-79). In all these cells, these PLC $\gamma$ isoforms modulate TLR signaling through multiple mechanisms (reviewed in ref. 80). In addition, several GPCR-activated PLC $\beta$ isoforms have been detected in immune cells, playing key roles in the differentiation and activation of both innate and adaptive immune responses, with increases in free calcium and PKC activity being essential $(69,81)$. Recently, PLC $\delta$ was shown to act as a negative regulator of macrophage-mediated phagocytosis (82).

\section{PLD signaling in innate immune cells}

PLD enzymes hydrolyze PC, the most abundant external-facing PL, generating phosphatidic acid (PA) and choline (Figure 3A). They are activated in response to several GPCRs and RTKs (reviewed in ref. 83). PA has a number of critical functions in innate immune signaling. With a small, negatively charged headgroup, PA induces negative curvature thought to be important for production of vesicles and membrane fusion, thus playing a central role in membrane remodeling (84). PA also acts as an intracellular signal, binding several cellular proteins, including the guanine nucleotide exchange factors (GEFs) DOCK2 and SOS, which activate Rac1 and Ras, while the PA-binding domain of CAMP-PDE4A1 has been clearly defined (85-87). Innate immune cells and platelets express the isomers PLD1 and PLD2, both known to play key roles in thrombotic disease (88-91). $P l d 1^{-/}$mice exhibit reduced $\alpha_{\mathrm{IIb}} \beta_{3}$-dependent platelet activation, rendering them resistant to pathological hemostasis events such as strokes and pulmonary embolisms (92). Studies in knockout mice and the use of isoform-specific inhibitors indicated that PLD1, but not PLD2, is required for neutrophil ROS production (93). The concerted action of PLD and PLA $A_{2}$ leads to formation of lysoPA, generated by thrombin-stimulated platelets, and is potentially able to stimulate aggregation itself via GPCR signaling (ref. 94 and Figure 3A); this is in addition to lysoPA generated by the action of autotaxin (lysoPLD) upon lysoPC.

\section{Phosphoinositides}

The seven phosphoinositides, PI(3)P, PI(4)P, PI(5)P, PI(3,4) P2, PI $(4,5) \mathrm{P} 2$, PI $(3,5) \mathrm{P} 2$, and PIP3, each demonstrate signaling capabilities (Figure 3B). The phosphoinositide 3-kinase (PI3K) enzymes catalyze hydroxyl group phosphorylation at the 3 position of the inositol headgroup of PI and its phosphorylated derivatives. The eight mammalian PI3K enzymes sort into three groups: class I (PI3K $\alpha, \beta, \gamma, \delta$ ), class II (PI3KC2 $\alpha, \beta, \gamma)$, and class III (vps34). Class I PI3Ks phosphorylate PIP2 to generate phosphatidylinositol 3,4,5-trisphosphate (PIP3). Class II enzymes can phosphorylate both PI and PI(4)P to generate PI(3)P or PI $(3,4)$ P2 on endosomes and the plasma membrane. Finally, class III enzyme solely phosphorylates PI, producing PI(3)P on endosomes, which also plays a key role in autophagy (95).

Class IA PI3Ks (PI3K $\alpha$ and PI3K $\beta$ ) are ubiquitously expressed, while PI3K $\delta$ is restricted to myeloid and lymphoid cells (reviewed in ref. 96). The class IB isoform, PI $3 \mathrm{~K} \gamma$, is differentially expressed, but is most highly expressed in myeloid cells. Each class IA PI3K $-\mathrm{PI} 3 \mathrm{~K} \alpha, \beta$, and $\delta$ - comprises one of five homologous regulatory

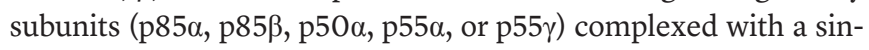
gle p110 subunit, whereas PI3K $\gamma$ is made up of $\mathrm{p} 110 \gamma$ and either a 
p84 or a p101 regulatory subunit. The soluble PI3Ks are recruited to the plasma membrane following receptor occupation. Antigen receptors, Fc receptors, integrins, cytokine receptors, and RTKs such as colony-stimulating factor (CSF) stimulate PI3K $\alpha, \beta$, and $\gamma$ activity through tyrosine phosphorylation with the $\mathrm{SH} 2$ domains in the regulatory domain, binding to the phosphotyrosine residues. GPCRs such as fMLP activate PI3K $\gamma$ through G $\beta \gamma$ subunits binding to $\mathrm{p} 84$ or $\mathrm{p} 101$ and to $\mathrm{p} 110 \gamma$. G $\beta \gamma$ has also been shown to bind to and thus activate $\mathrm{p} 110 \beta$. Membrane association is further promoted by binding of the Ras-binding domain of the 1110 subunits, associating with either Ras $(\mathrm{p} 110 \alpha, \delta, \gamma)$ or Rac $(\mathrm{p} 110 \beta)$.

PI3K activity generates PIP3, which binds to $\mathrm{PH}$ domains in target proteins and activates signaling cascades. The phosphorylation and activation of the serine kinase PKB (also known as AKT) is a ubiquitous response to PI3K activation that can activate TORC1 to promote cell growth, but also activates a metabolic shift, as in cytotoxic T lymphocyte activation (97). PKB also phosphorylates and inhibits the nuclear localization of FOXO transcription factors critical in lymphocyte differentiation. PIP3 is dephosphorylated to regenerate $\mathrm{PI}(4,5) \mathrm{P} 2$ by $\mathrm{PTEN}$, but can also generate $\mathrm{PI}(3,4) \mathrm{P} 2$ through SHIP1/2 activity (98). PI(4,5) P2 also binds PH domaincontaining proteins, and, while many of these also bind PIP3, there is $\mathrm{PI}(3,4) \mathrm{P} 2$ selectivity, notably DAPP-1 (96). Lipidomic analysis has shown that PIP3 is not a single molecular species, with C36:1, C36:2, C36:3, C36:4, C38:2, C38:3, C38:4, and C38:5 being detected in neutrophils and macrophages $(99,100)$. This variety may enable further selectivity in binding of different $\mathrm{PH}$ domain proteins and thus downstream signaling (100).

The field's understanding of the distinct roles of PI3K isoforms has benefited from the generation of knockout mice and selective small-molecule inhibitors. These approaches have provided evidence that $\mathrm{PI} 3 \mathrm{~K} \gamma$ is critical for extravasation and migration of neutrophils, monocytes, and eosinophils to inflammatory sites, with additional PI3K $\delta$ involvement possibly occurring through integrin-mediated activation. PI3K $\beta$ and $\delta$ regulate immune cell spreading and activation by mediating cell surface attachment to extracellular matrix or pathogens, such as fungi, and both isoforms are necessary for a maximal ROS response (101). In addition, PI3K activity stimulates Rac through PIP3 regulation of GEFs and GTPase-activating proteins, leading to regulation of the actin cytoskeleton.

The development, proliferation, and differentiation of B and $\mathrm{T}$ cells are stringently regulated by PI3K activity, which involves PIP3-regulated signaling, including control of FOXO/FoxP3. However, PIP3 also activates BTK, which phosphorylates and stimulates PLC $\gamma$-producing DAG and calcium signaling that are important for both B cell proliferation and cytokine synthesis (102). There has been extensive development of PI3K inhibitors, and number have been approved for clinical use (103), particularly PI3K $\delta$ inhibitors to treat chronic lymphocytic leukemia (104). The importance of the PI3K pathway in human immune disorders is further emphasized by the presence of activating mutations in $\mathrm{p} 110 \delta$ in a number of primary immune deficiency patients, who suffer particularly from recurring respiratory tract infections (105). In contrast, deficiency in PI3K $\delta$ signaling decreases Treg number and increases neutrophil numbers, which can cause an increase in endotoxic shock-related mortality (106).

\section{PLs as ligands for innate-like T cell populations}

Most immunologists consider $\mathrm{T}$ cell immunity only in the context of recognition of peptides when presented by MHC molecules (107). However, the family of MHC class I-like antigen-presenting molecules termed CD1 is ideally suited for capturing and displaying lipids for $\mathrm{T}$ cell surveillance (2). This evolutionarily conserved CD1 antigen-presenting family is subdivided into group 1 (CD1a, $\mathrm{CD} 1 \mathrm{~b}$, and CD1c) and group 2 (CD1d) members. CD1 group 1 is absent in mice; thus our understanding of its role in immunity is less developed as compared with CD1d, which is present in mice and humans $(108,109)$. Each CD1 isoform has distinct atomic architectures (110) and cellular trafficking properties, thereby enabling a broad array of lipid classes (including PLs) that can represent either foreign or self-antigens to be bound.

Distinct populations of $\mathrm{T}$ cells subsequently recognize these CD1-lipid complexes. Lipid-reactive T cells play key roles in protective immunity, cancer, autoimmunity, and allergies. The most well-characterized lipid-reactive $\mathrm{T}$ cells are the innate-like type I natural killer T cells (NKT cells), which are restricted to the CD1d molecule (2). Type I NKT cells rapidly secrete high amounts of a range of cytokines upon activation and have shown broad therapeutic promise (109).

Lipid-reactive $\mathrm{T}$ cells can specifically respond to a range of CD1-presented lipids, including PLs, a major lipid component of mammalian membranes. Indeed, subsets of type I NKT cells have exhibited autoreactivity toward PI, PE, and plasmalogen lysoPE (p-lysoPE) (111-113). While the physiological role of NKT autoreactivity toward common PLs remains unclear, reactivity toward certain lysoPLs, including lysoPC, is reported to be associated with inflammatory responses (114). Interestingly, p-lysoPE is an ether-linked PL that is generated in the peroxisome and is thought to play a role in the development of NKT cells (115). Further, infection by hepatitis B virus (HBV) alters the levels of lipids, including lysoPLs within hepatocytes, which subsequently results in NKT cell activation, thereby playing a role in protective immunity (116).

The functional properties, T cell receptor (TCR) repertoire, and antigen reactivity of type II NKT cells are distinct from those of type I NKT cells (1). Type II NKT cells are also described as responsive to bacterially derived PLs, including PI and PG from Mycobacterium tuberculosis, suggesting a role in protective immunity toward this devastating pathogen (4). PG from Listeria monocytogenes was also shown to potently activate a subset of type II NKT cells (3).

Members of CD1 group 1 also present PLs, and T cell reactivity toward certain pollen-derived PLs has been associated with allergies $(117,118)$. Further, CD1a, which is expressed predominantly in the skin and naturally presents skin-derived oils (119), is associated with contact hypersensitivities (120) as well as bee sting allergies owing to phospholipase activity derived from bee venom-generating LPLs that cause an inflammatory skin response $(121,122)$. Moreover, aberrant reactivity toward CD1a-presented PLs is also implicated in allergies toward house dust mites (123). CD1b-mediated autoreactivity toward rare mammalian PLs, including PG, has also recently been described and implicated in some autoimmune conditions $(124,125)$.

The conundrum of how lipid-reactive $\mathrm{T}$ cells distinguish between rare and common PLs was recently determined to arise from the ideal shape and charge complementarity between the TCR and CD1b-PG complex, whereas the polar headgroups of 
more common PLs are sterically disfavored from binding to the TCR (5). Further, T cell targeting of specific PLs, including methyl-lysophosphatidic acid (mLPA), when presented by $\mathrm{CD} 1 \mathrm{c}^{+}$leukemic cells is considered to play a role in antitumor immunity and hence may represent a likely candidate for novel immunotherapeutic approaches (6). Collectively, T cell reactivity toward CD1-restricted PLs is emerging as a component of protective and aberrant immunity, although the breadth of reactivity toward distinct PLs and their role in physiology and pathophysiology remain germinal.

\section{Summary}

Herein, we summarized the major PL-dependent signaling pathways in circulating innate immune cells and their recognition by specialized populations of innate $\mathrm{T}$ cells during challenge. The importance of PLs in the acute response to injury extends far beyond their structural role, as they provide a major repository for activation-dependent signaling molecules such as prostaglandins, oxylipins, and PAF during acute injury and inflammation and through $\mathrm{T}$ cell recognition, representing a way for the body to sense danger and appropriately respond during challenge. Importantly, PL-dependent signaling is mediated not only through long-known soluble paracrine mediators (oxylipins such as prostaglandins), but also through changing membrane biophysics that alter protein binding and activation on both the outside and the inside of cells (eoxPL, phosphoinositides). Many questions remain in the emerging study of PL signaling, particularly relating to how PLs dynamically change, the role(s) of CoA-dependent versus -independent recycling pathways in their metabolism, how tissues recognize endogenous changes and respond, and ultimately how to harness these processes to improve detection, diagnosis, and treatment of human disease associated with aberrant PL generation and signaling.

\section{Acknowledgments}

Funding is acknowledged from the Wellcome Trust (094143/Z/ 10/Z), the British Heart Foundation (RG/12/11/29815), and the European Research Council (LipidArrays) to VBO, and from the Australian Research Council and the National Health and Medical Research Council to JR. JR is supported by an Australian Research Council Laureate Fellowship. VBO is a Royal Society Wolfson Research Merit Award Holder. MJOW acknowledges funding from the Biotechnology and Biological Sciences Research Council (BB/ P013384/1) and the Medical Research Council (MR/M004821/1). MJOW and VBO acknowledge funding for LIPID MAPS from the Wellcome Trust (203014/Z/16/Z). All structures of lipids generated in the figures used the LIPID MAPS online structure drawing tool (http://www.lipidmaps.org/).

Address correspondence to: Valerie B. O'Donnell, Systems Immunity Research Institute, Cardiff University, Heath Park, Cardiff, CF14 4XN, United Kingdom. Phone: 44.2920.687313; Email: o-donnellvb@cardiff.ac.uk.
1. Rossjohn J, Pellicci DG, Patel O, Gapin L, Godfrey DI. Recognition of CD1d-restricted antigens by natural killer T cells. Nat Rev Immunol. 2012;12(12):845-857.

2. Van Rhijn I, Godfrey DI, Rossjohn J, Moody DB. Lipid and small-molecule display by CD1 and MR1. Nat Rev Immunol. 2015;15(10):643-654.

3. Wolf BJ, et al. Identification of a potent microbial lipid antigen for diverse NKT cells. J Immunol. 2015;195(6):2540-2551.

4. Tatituri RV, et al. Recognition of microbial and mammalian phospholipid antigens by NKT cells with diverse TCRs. Proc Natl Acad Sci U S A. 2013;110(5):1827-1832.

5. Shahine A, et al. A molecular basis of human T cell receptor autoreactivity toward self-phospholipids. Sci Immunol. 2017;2(16):eaao1384.

6. Lepore M, de Lalla C, Mori L, Dellabona P, De Libero G, Casorati G. Targeting leukemia by CD1c-restricted T cells specific for a novel lipid antigen. Oncoimmunology. 2015;4(3):e970463.

7. Lepore $\mathrm{M}$, et al. A novel self-lipid antigen targets human T cells against CD1c(+) leukemias. J Exp Med. 2014;211(7):1363-1377.

8. Haban P, Zidekova E, Klvanova J. Supplementation with long-chain n-3 fatty acids in noninsulin-dependent diabetes mellitus (NIDDM) patients leads to the lowering of oleic acid content in serum phospholipids. Eur J Nutr. 2000;39(5):201-206.

9. Siener R, et al. Change in the fatty acid pattern of erythrocyte membrane phospholipids after oral supplementation of specific fatty acids in patients with gastrointestinal diseases. Eur J Clin Nutr. 2010;64(4):410-418.
10. Colas RA, Shinohara M, Dalli J, Chiang N, Serhan $\mathrm{CN}$. Identification and signature profiles for pro-resolving and inflammatory lipid mediators in human tissue. Am J Physiol Cell Physiol. 2014;307(1):C39-C54.

11. Kalish BT, et al. Intravenous fish oil lipid emulsion promotes a shift toward anti-inflammatory proresolving lipid mediators. Am J Physiol Gastro intest Liver Physiol. 2013;305(11):G818-G828.

12. Lundström SL, et al. Lipid mediator serum profiles in asthmatics significantly shift following dietary supplementation with omega-3 fatty acids. Mol Nutr Food Res. 2013;57(8):1378-1389.

13. Mas E, Croft KD, Zahra P, Barden A, Mori TA. Resolvins D1, D2, and other mediators of self-limited resolution of inflammation in human blood following n-3 fatty acid supplementation. Clin Chem. 2012;58(10):1476-1484.

14. Psychogios N, et al. The human serum metabolome. PLoS One. 2011;6(2):e16957.

15. Skarke C, et al. Bioactive products formed in humans from fish oils. JLipid Res. 2015;56(9):1808-1820.

16. Kennedy EP. Biosynthesis of complex lipids. Fed Proc. 1961;20:934-940.

17. Kennedy EP, Weiss SB. The function of cytidine coenzymes in the biosynthesis of phospholipides. J Biol Chem. 1956;222(1):193-214.

18. Lands WE. Metabolism of glycerolipides; a comparison of lecithin and triglyceride synthesis. J Biol Chem. 1958;231(2):883-888.

19. Marder VJ, et al. Analysis of thrombi retrieved from cerebral arteries of patients with acute ischemic stroke. Stroke. 2006;37(8):2086-2093.

20. Niesten JM, et al. Histopathologic composition of cerebral thrombi of acute stroke patients is correlated with stroke subtype and thrombus attenuation. PLoS One. 2014;9(2):e88882.

21. Yunoki K, et al. Relationship of thrombus characteristics to the incidence of angiographically visible distal embolization in patients with ST-segment elevation myocardial infarction treated with thrombus aspiration. JACC Cardiovasc Interv. 2013;6(4):377-385.

22. Dennis EA, Cao J, Hsu YH, Magrioti V, Kokotos G. Phospholipase A2 enzymes: physical structure, biological function, disease implication, chemical inhibition, and therapeutic intervention. Chem Rev. 2011;111(10):6130-6185.

23. Thomas LM, Holub BJ. Eicosanoid-dependent and -independent formation of individual [14C] stearoyl-labelled lysophospholipids in collagen-stimulated human platelets. Biochim Biophys Acta. 1991;1081(1):92-98.

24. Stafforini DM, Zimmerman GA. Unraveling the PAF-AH/Lp-PLA2 controversy. J Lipid Res. 2014;55(9):1811-1814.

25. Leslie CC. Cytosolic phospholipase $\mathrm{A}_{2}$ : physiological function and role in disease. J Lipid Res. 2015;56(8):1386-1402.

26. Wong DA, Kita Y, Uozumi N, Shimizu T. Discrete role for cytosolic phospholipase $\mathrm{A}(2) \alpha$ in platelets: studies using single and double mutant mice of cytosolic and group IIA secretory phospholipase A(2). JExp Med. 2002;196(3):349-357.

27. Yoda E, et al. Group VIB calcium-independent phospholipase A2 (iPLA2 $\gamma$ ) regulates platelet activation, hemostasis and thrombosis in mice. PLoS One. 2014;9(10):e109409.

28. Cathcart MK. Signal-activated phospholipase 
regulation of leukocyte chemotaxis. J Lipid Res. 2009;50(suppl):S231-S236.

29. Murakami M, Sato H, Miki Y, Yamamoto K, Taketomi Y. A new era of secreted phospholipase $\mathrm{A}_{2}$. JLipid Res. 2015;56(7):1248-1261.

30. Slatter DA, et al. Mapping the human platelet lipidome reveals cytosolic phospholipase $\mathrm{A} 2$ as a regulator of mitochondrial bioenergetics during activation. Cell Metab. 2016;23(5):930-944.

31. Bolen AL, et al. The phospholipase A1 activity of lysophospholipase A-I links platelet activation to LPA production during blood coagulation. J Lipid Res. 2011;52(5):958-970.

32. Ramanadham S, Ali T, Ashley JW, Bone RN, Hancock WD, Lei X. Calcium-independent phospholipases A2 and their roles in biological processes and diseases. JLipid Res. 2015;56(9):1643-1668.

33. Daleke DL. Phospholipid flippases. J Biol Chem. 2007;282(2):821-825.

34. Ravichandran KS. Find-me and eat-me signals in apoptotic cell clearance: progress and conundrums. J Exp Med. 2010;207(9):1807-1817.

35. Heemskerk JW, Bevers EM, Lindhout T. Platelet activation and blood coagulation. Thromb Haemost. 2002;88(2):186-193.

36. Zwaal RF, Comfurius P, Bevers EM. Surface exposure of phosphatidylserine in pathological cells. Cell Mol Life Sci. 2005;62(9):971-988.

37. Weiss HJ. Scott syndrome: a disorder of platelet coagulant activity. Semin Hematol. 1994;31(4):312-319.

38. Picollo A, Malvezzi M, Accardi A. TMEM16 proteins: unknown structure and confusing functions. J Mol Biol. 2015;427(1):94-105.

39. Lauder SN, et al. Networks of enzymatically oxidized membrane lipids support calciumdependent coagulation factor binding to maintain hemostasis. Sci Signal. 2017;10(507):eaan2787.

40. Morgan LT, Thomas CP, Kühn H, O'Donnell VB. Thrombin-activated human platelets acutely generate oxidized docosahexaenoic-acid-containing phospholipids via 12-lipoxygenase. Biochem J. 2010;431(1):141-148.

41. Clark SR, et al. Characterization of platelet aminophospholipid externalization reveals fatty acids as molecular determinants that regulate coagulation. Proc Natl Acad Sci US A. 2013;110(15):5875-5880.

42. Whyte CS, et al. Plasminogen associates with phosphatidylserine-exposing platelets and contributes to thrombus lysis under flow. Blood. 2015;125(16):2568-2578

43. Andree HA, Reutelingsperger CP, Hauptmann R, Hemker HC, Hermens WT, Willems GM. Binding of vascular anticoagulant alpha (VAC alpha) to planar phospholipid bilayers. J Biol Chem . 1990;265(9):4923-4928.

44. Koopman G, Reutelingsperger CP, Kuijten GA, Keehnen RM, Pals ST, van Oers MH. Annexin V for flow cytometric detection of phosphatidylserine expression on $\mathrm{B}$ cells undergoing apoptosis. Blood.1994;84(5):1415-1420.

45. Meers P, Mealy T. Phospholipid determinants for annexin $\mathrm{V}$ binding sites and the role of tryptophan 187. Biochemistry. 1994;33(19):5829-5837.

46. Otzen DE, Blans K, Wang H, Gilbert GE, Rasmussen JT. Lactadherin binds to phosphatidylserine-containing vesicles in a two-step mech- anism sensitive to vesicle size and composition. Biochim Biophys Acta. 2012;1818(4):1019-1027.

47. Shi J, Gilbert GE. Lactadherin inhibits enzyme complexes of blood coagulation by competing for phospholipid-binding sites. Blood. 2003;101(7):2628-2636.

48. Iba T, Hashiguchi N, Nagaoka I, Tabe Y, Murai M. Neutrophil cell death in response to infection and its relation to coagulation. J Intensive Care. 2013;1(1):13.

49. Cole AL, Subbanagounder G, Mukhopadhyay S, Berliner JA, Vora DK. Oxidized phospholipidinduced endothelial cell/monocyte interaction is mediated by a cAMP-dependent R-Ras/PI3kinase pathway. Arterioscler Thromb Vasc Biol. 2003;23(8):1384-1390.

50. Lee H, et al. Role for peroxisome proliferatoractivated receptor alpha in oxidized phospholipid-induced synthesis of monocyte chemotactic protein-1 and interleukin- 8 by endothelial cells. Circ Res. 2000;87(6):516-521.

51. Loidl A, Sevcsik E, Riesenhuber G, Deigner HP, Hermetter A. Oxidized phospholipids in minimally modified low density lipoprotein induce apoptotic signaling via activation of acid sphingomyelinase in arterial smooth muscle cells. J Biol Chem. 2003;278(35):32921-32928.

52. O'Donnell VB, Murphy RC. New families of bioactive oxidized phospholipids generated by immune cells: identification and signaling actions. Blood. 2012;120(10):1985-1992.

53. DeFilippis AP, et al. Circulating levels of plasminogen and oxidized phospholipids bound to plasminogen distinguish between atherothrombotic and non-atherothrombotic myocardial infarction. J Thromb Thrombolysis. 2016;42(1):61-76.

54. Aldrovandi $\mathrm{M}$, et al. Human platelets generate phospholipid-esterified prostaglandins via cyclooxygenase- 1 that are inhibited by low dose aspirin supplementation. J Lipid Res. 2013;54(11):3085-3097.

55. Aldrovandi M, et al. DioxolaneA3-phosphatidylethanolamines are generated by human platelets and stimulate neutrophil integrin expression. Redox Biol. 2017;11:663-672.

56. Clark SR, et al. Esterified eicosanoids are acutely generated by 5 -lipoxygenase in primary human neutrophils and in human and murine infection. Blood. 2011;117(6):2033-2043.

57. Hammond VJ, et al. Novel keto-phospholipids are generated by monocytes and macrophages, detected in cystic fibrosis, and activate peroxisome proliferator-activated receptor- $\gamma$. J Biol Chem. 2012;287(50):41651-41666.

58. Maskrey BH, et al. Activated platelets and monocytes generate four hydroxyphosphatidylethanolamines via lipoxygenase. J Biol Chem. 2007;282(28):20151-20163.

59. Morgan AH, et al. Phosphatidylethanolamineesterified eicosanoids in the mouse: tissue localization and inflammation-dependent formation in Th-2 disease. J Biol Chem. 2009;284(32):21185-21191.

60. O'Connor A, et al. LipidFinder: a computational workflow for discovery of lipids identifies eicosanoid-phosphoinositides in platelets. JCI Insight. 2017;2(7):e91634.

61. Kühn H, O'Donnell VB. Inflammation and immune regulation by 12/15-lipoxygenases. Prog Lipid Res. 2006;45(4):334-356.

62. Klett EL, Chen S, Yechoor A, Lih FB, Coleman RA. Long-chain acyl-CoA synthetase isoforms differ in preferences for eicosanoid species and long-chain fatty acids. J Lipid Res. 2017;58(5):884-894.

63. Uderhardt S, et al. Enzymatic lipid oxidation by eosinophils propagates coagulation, hemostasis, and thrombotic disease. JExp Med. 2017;214(7):2121-2138.

64. Montrucchio G, Alloatti G, Camussi G. Role of platelet-activating factor in cardiovascular pathophysiology. Physiol Rev. 2000;80(4):1669-1699.

65. Barnes PJ, Chung KF, Page CP. Platelet-activating factor as a mediator of allergic disease. J Allergy Clin Immunol. 1988;81(5 pt 1):919-934.

66. Snyder F. Chemical and biochemical aspects of platelet activating factor: a novel class of acetylated ether-linked choline-phospholipids. Med Res Rev. 1985;5(1):107-140.

67. Snyder F. Platelet-activating factor and related acetylated lipids as potent biologically active cellular mediators. Am J Physiol. 1990; 259(5 pt 1):C697-C708.

68. Palur Ramakrishnan AV, Varghese TP, Vanapalli S, Nair NK, Mingate MD. Platelet activating factor: a potential biomarker in acute coronary syndrome? Cardiovasc Ther. 2017;35(1):64-70.

69. Cocco L, Follo MY, Manzoli L, Suh PG. Phosphoinositide-specific phospholipase $\mathrm{C}$ in health and disease. J Lipid Res. 2015;56(10):1853-1860.

70. Zheng Y, et al. Restoration of responsiveness of phospholipase $\mathrm{C} \gamma 2$-deficient platelets by enforced expression of phospholipase C $\gamma 1$. PLoS One. 2015;10(3):e0119739.

71. Mangin P, et al. A PLC $\gamma 2$-independent platelet collagen aggregation requiring functional association of GPVI and integrin $\alpha 2 \beta 1$. FEBS Lett. 2003;542(1-3):53-59.

72. Munnix IC, et al. The glycoprotein VI-phospholipase $\mathrm{C} \gamma 2$ signaling pathway controls thrombus formation induced by collagen and tissue factor in vitro and in vivo. Arterioscler Thromb Vasc Biol. 2005;25(12):2673-2678.

73. Suzuki-Inoue K, et al. A novel Syk-dependent mechanism of platelet activation by the C-type lectin receptor CLEC-2. Blood. 2006;107(2):542-549.

74. Suzuki-Inoue K, Inoue O, Frampton J, Watson SP. Murine GPVI stimulates weak integrin activation in PLC $\gamma 2$ - platelets: involvement of PLC $\gamma 1$ and PI3-kinase. Blood. 2003;102(4):1367-1373.

75. Suzuki-Inoue K, et al. Involvement of Src kinases and PLC $\gamma 2$ in clot retraction. Thromb Res. 2007;120(2):251-258.

76. Caraux A, et al. Phospholipase C- $\gamma 2$ is essential for NK cell cytotoxicity and innate immunity to malignant and virally infected cells. Blood. 2006;107(3):994-1002.

77. Jakus Z, Simon E, Frommhold D, Sperandio M, Mócsai A. Critical role of phospholipase $\mathrm{C} \gamma 2$ in integrin and Fc receptor-mediated neutrophil functions and the effector phase of autoimmune arthritis. JExp Med. 2009;206(3):577-593.

78. Ting AT, Karnitz LM, Schoon RA, Abraham RT, Leibson PJ. Fc $\gamma$ receptor activation induces the tyrosine phosphorylation of both phospholipase C (PLC) $-\gamma 1$ and PLC- $\gamma 2$ in natural killer cells. 
JExp Med.1992;176(6):1751-1755.

79. Wen R, Jou ST, Chen Y, Hoffmeyer A, Wang D. Phospholipase $\mathrm{C} \gamma 2$ is essential for specific functions of Fc\&R and Fc $\gamma$ R. JImmunol. 2002;169(12):6743-6752.

80. Bae YS, Lee HY, Jung YS, Lee M, Suh PG. Phospholipase $\mathrm{C} \gamma$ in Toll-like receptor-mediated inflammation and innate immunity. Adv Biol Regul. 2017;63:92-97.

81. Kawakami T, Xiao W. Phospholipase C- $\beta$ in immune cells. Adv Biol Regul. 2013;53(3):249-257.

82. Kudo K, Uchida T, Sawada M, Nakamura Y, Yoneda A, Fukami K. Phospholipase C $\delta 1$ in macrophages negatively regulates TLR4-induced proinflammatory cytokine production and $\mathrm{F} \gamma \gamma$ receptor-mediated phagocytosis. Adv Biol Regul. 2016;61:68-79.

83. Selvy PE, Lavieri RR, Lindsley CW, Brown HA. Phospholipase D: enzymology, functionality, and chemical modulation. Chem Rev. 2011;111(10):6064-6119.

84. Ammar MR, Kassas N, Chasserot-Golaz S, Bader MF, Vitale N. Lipids in regulated exocytosis: what are they doing? Front Endocrinol (Lausanne). 2013;4:125.

85. Baillie GS, et al. TAPAS-1, a novel microdomain within the unique $\mathrm{N}$-terminal region of the PDE4A1 cAMP-specific phosphodiesterase that allows rapid, $\mathrm{Ca}^{2+}$-triggered membrane association with selectivity for interaction with phosphatidic acid. J Biol Chem. 2002;277(31):28298-28309.

86. Nishikimi A, et al. Sequential regulation of DOCK2 dynamics by two phospholipids during neutrophil chemotaxis. Science. 2009;324(5925):384-387.

87. Zhao C, Du G, Skowronek K, Frohman MA, BarSagi D. Phospholipase D2-generated phosphatidic acid couples EGFR stimulation to Ras activation by Sos. Nat Cell Biol. 2007;9(6):706-712.

88. Elvers $\mathrm{M}$, et al. Impaired $\alpha(\mathrm{IIb}) \beta(3)$ integrin activation and shear-dependent thrombus formation in mice lacking phospholipase D1. Sci Signal. 2010;3(103):ra1.

89. Hong KW, et al. Non-synonymous singlenucleotide polymorphisms associated with blood pressure and hypertension. JHum Hypertens. 2010;24(11):763-774.

90. Schönberger T, et al. Pivotal role of phospholipase D1 in tumor necrosis factor- $\alpha$-mediated inflammation and scar formation after myocardial ischemia and reperfusion in mice. Am J Pathol. 2014;184(9):2450-2464.

91. Stegner D, Thielmann I, Kraft P, Frohman MA, Stoll G, Nieswandt B. Pharmacological inhibition of phospholipase $D$ protects mice from occlusive thrombus formation and ischemic stroke-brief report. Arterioscler Thromb Vasc Biol. 2013;33(9):2212-2217.

92. Elvers M, et al. Impaired $\alpha(\operatorname{IIb}) \beta(3)$ integrin activation and shear-dependent thrombus formation in mice lacking phospholipase D1. Sci Signal. 2010;3(103):ra1.

93. Norton LJ, et al. PLD1 rather than PLD2 regulates phorbol-ester-, adhesion-dependent and F $\gamma$ receptor-stimulated ROS production in neutrophils. JCell Sci. 2011;124(pt 12):1973-1983.

94. Eichholtz T, Jalink K, Fahrenfort I, Moolenaar WH. The bioactive phospholipid lysophosphatidic acid is released from activated platelets. Biochem J. 1993;291(pt 3):677-680.

95. Axe EL, et al. Autophagosome formation from membrane compartments enriched in phosphatidylinositol 3-phosphate and dynamically connected to the endoplasmic reticulum. JCell Biol. 2008;182(4):685-701.

96. Hawkins PT, Stephens LR. PI3K signalling in inflammation. Biochim Biophys Acta. 2015;1851(6):882-897.

97. Engelman JA, Luo J, Cantley LC. The evolution of phosphatidylinositol 3-kinases as regulators of growth and metabolism. Nat Rev Genet. 2006;7(8):606-619.

98. Rudge SA, Wakelam MJ. Phosphatidylinositolphosphate phosphatase activities and cancer. JLipid Res. 2016;57(2):176-192.

99. Milne SB, Ivanova PT, DeCamp D, Hsueh RC, Brown HA. A targeted mass spectrometric analysis of phosphatidylinositol phosphate species. J Lipid Res. 2005;46(8):1796-1802.

100.Wakelam MJ. The uses and limitations of the analysis of cellular phosphoinositides by lipidomic and imaging methodologies. Biochim Biophys Acta. 2014;1841(8):1102-1107.

101. Kulkarni S, et al. PI3K $\beta$ plays a critical role in neutrophil activation by immune complexes. Sci Signal. 2011;4(168):ra23.

102. Fruman DA, Bismuth G. Fine tuning the immune response with PI3K. Immunol Rev. 2009;228(1):253-272.

103. Fruman DA, Chiu H, Hopkins BD, Bagrodia S, Cantley LC, Abraham RT. The PI3K pathway in human disease. Cell. 2017;170(4):605-635.

104.Pongas G, Cheson BD. PI3K signaling pathway in normal B cells and indolent B-cell malignancies. Semin Oncol. 2016;43(6):647-654.

105.Lucas CL, Chandra A, Nejentsev S, Condliffe AM, Okkenhaug K. PI3K $\delta$ and primary immunodeficiencies. Nat Rev Immunol. 2016;16(11):702-714.

106. Okeke EB, Mou Z, Onyilagha N, Jia P, Gounni AS, Uzonna JE. Deficiency of phosphatidylinositol 3-kinase $\delta$ signaling leads to diminished numbers of regulatory $\mathrm{T}$ cells and increased neutrophil activity resulting in mortality due to endotoxic shock. JImmunol. 2017;199(3):1086-1095.

107. Rossjohn J, Gras S, Miles JJ, Turner SJ, Godfrey DI, McCluskey J. T cell antigen receptor recognition of antigen-presenting molecules. Annu Rev Immunol. 2015;33:169-200.

108. Godfrey DI, Pellicci DG, Patel O, Kjer-Nielsen L, McCluskey J, Rossjohn J. Antigen recognition by CD1d-restricted NKT T cell receptors. Semin Immunol. 2010;22(2):61-67.

109. Godfrey DI, Uldrich AP, McCluskey J, Rossjohn J, Moody DB. The burgeoning family of unconventional T cells. Nat Immunol. 2015;16(11):1114-1123.

110.Adams EJ, Luoma AM. The adaptable major histocompatibility complex (MHC) fold: structure and function of nonclassical and MHC class I-like molecules. Annu Rev Immunol. 2013;31:529-561.

111. Gapin L, Godfrey DI, Rossjohn J. Natural Killer T cell obsession with self-antigens. Curr Opin Immunol. 2013;25(2):168-173.

112. Mallevaey T, et al. A molecular basis for NKT cell recognition of CD1d-self-antigen. Immunity. 2011;34(3):315-326.

113. Gumperz JE, et al. Murine CD1d-restricted T cell recognition of cellular lipids. Immunity. 2000;12(2):211-221.

114. Fox LM, et al. Recognition of lyso-phospholipids by human natural killer T lymphocytes. PLoS Biol. 2009;7(10):e1000228.

115. Facciotti F, et al. Peroxisome-derived lipids are self antigens that stimulate invariant natural killer T cells in the thymus. Nat Immunol. 2012;13(5):474-480.

116. Zeissig S, et al. Hepatitis B virus-induced lipid alterations contribute to natural killer T cell-dependent protective immunity. Nat Med. 2012;18(7):1060-1068.

117. Agea E, et al. Human CD1-restricted T cell recognition of lipids from pollens. J Exp Med. 2005;202(2):295-308.

118. Russano AM, et al. Recognition of pollenderived phosphatidyl-ethanolamine by human CD1d-restricted $\gamma \delta$ T cells. J Allergy Clin Immunol. 2006;117(5):1178-1184.

119. de Jong A, et al. CD1a-autoreactive $\mathrm{T}$ cells recognize natural skin oils that function as headless antigens. Nat Immunol. 2014;15(2):177-185.

120. Kim JH, et al. CD1a on Langerhans cells controls inflammatory skin disease. Nat Immunol. 2016;17(10):1159-1166

121. Subramaniam S, et al. Elevated and crossresponsive CD1a-reactive $\mathrm{T}$ cells in bee and wasp venom allergic individuals. Eur J Immunol. 2016;46(1):242-252.

122. Bourgeois EA, et al. Bee venom processes human skin lipids for presentation by CD1a. J Exp Med. 2015;212(2):149-163.

123. Jarrett $R$, et al. Filaggrin inhibits generation of CD1a neolipid antigens by house dust mite-derived phospholipase. Sci Transl Med. 2016;8(325):325ra18.

124.Van Rhijn I, et al. Human autoreactive T cells recognize CD1b and phospholipids. Proc Natl Acad Sci U S A. 2016;113(2):380-385.

125. Bagchi S, et al. CD1b-autoreactive T cells contribute to hyperlipidemia-induced skin inflammation in mice. J Clin Invest. 2017;127(6):2339-2352. 